\title{
Döner Tamburlu Makina ile Hasat Edilen Fĭg + Triti- kale Karışımı Haylaj Üretiminin Enerji Bilançosu
}

\author{
Energy Balance of Vetch + Triticale Mix Haylage Production Harvested by Rotary \\ Drum Machine
}

\section{Mehmet Emin BİLGÍLi ${ }^{*}$}

\section{Yasemin VURARAK ${ }^{2}$}

\section{Ahmet İNCE ${ }^{3}$}

${ }^{1,2}$ Doğu Akdeniz Tarımsal Araştırma Enstitüsü Müdürlüğü, Adana

${ }^{3}$ Çukurova Üniversitesi, Ziraat Fakültesi, Tarım

Makinaları ve Teknolojileri Mühendisliği Bölümü, Adana

\section{ORCID}

iD 0000-0002-4191-0540

iD 0000-0003-1048-788X

iD 0000-0002-5722-0552

\section{*Sorumlu yazar:}

eminbilgili@gmail.com

Destekleyen Kurum: TARIMSAL ARAŞTIRMALAR GENEL MÜDÜRLÜĞÜ (TAGEM)

Proje Numarası: TAGEM/TSKAD/ 14/A13/P08/06

Gönderilme Tarihi:

16 Ocak 2021

Kabul Tarihi

\section{ÖZET}

Bu çalışma, Adana ili koşullarında 2015-2017 yıllarındaki üretim döneminde 3 yıl süreyle yürütülmüştür. Yem bitkilerinden ekonomik ve kaliteli haylaj elde etmek amacıyla yapılmıştır. Döner tamburlu makina ile hasad edilen fiğ+tritikale karışımının biçilerek; kurumasının hızlandırılması sonucu uygulanan sistemler ile girdilerin ekonomik ve sürdürülebilirliği bakımından enerji kullanımı ile karşılaştırılmıştır. Enerji bilançosundaki amaç, tarımsal üretim uygulamalarında kullanılan toplam girdilerin enerji değerleri ile elde edilen ürünlerin enerji değerlerinin hesaplanması sonucu enerjinin ne kadar verimli kullanılıp kullanılmadığının belirlenmesidir. Bu bağlamda, ekonomik üretim ve çevrenin sürdürülebilirliği için tarımsal üretimde verimli enerji kullanımı önemlidir. Bu amaçla, üretimde kullanılan makinaların ve aletlerin ekonomik ömürleri, iş başarıları, yakıt ile yağ tüketimleri, makina ağırlıkları, gübre, tohum miktarları gibi temel veriler önceki çalışmalardan, değişik kaynak ve kataloglardan sağlanmıştır. Değerlendirmeler sonucunda haylajlık fiğ+tritikale yetiştiriciliğinde enerji çıktı/ girdi oranı 5.72, özgül enerji $1.59 \mathrm{MJkg}^{-1}$, net enerji değeri 80 804.63 MJha $^{-1}$ olarak hesaplanmıştır. Haylajlık fiğ+tritikale yetiştiriciliğinde toplam enerji girdileri içerisinde kullanım oranı en çok olanın \%35.39 ile ambalaj malzemeleri olduğu hesaplanmıştır. Bunu sırasıyla \%26.36 ile tohum, \%20.94 ile gübre enerjisi, \%13.78 ile yakıt-yağ ve \%3.16 ile makina işgücü 
enerjisi ve diğerleri takip etmiştir.

Sürdürülebilir çevre ve enerji açısından konu çalışanları, politika üreticileri ve karar vericiler için veri seti olarak kullanılabilir.

Anahtar Kelimeler: Haylaj, fiğ +tritikale üretimi, enerji bilançosu, Adana

\section{ABSTRACT}

This study was conducted in Adana province conditions for 3 years between the years 2015-2017 of production season. It was made in order to obtain economical and high quality haylage from forage plants. The mixture of vetch + triticale harvested by a rotating drum machine is cut; the systems applied as a result of the acceleration of drying are compared with the energy use in terms of economy and sustainability of inputs. Purpose in energy balance, the result of energy values calculation in the obtained products with the energy values of the total inputs used in agricultural production applications is important whether the energy is used effectively or not. In this context, efficient energy use in agricultural production is important for economic production and sustainability of the environment. For this purpose, the basic features of the machines and tools used in production such as their economic life, business success, fuel and oil consumption, machine weights, fertilizer, seed amounts were obtained from previous studies, different sources and catalogs. As a result of the evaluations, energy output/input rate 5.72, the specific energy value and net energy production in grown haylage vetch+triticale was calculated as, $1.59 \mathrm{MJkg}^{-1}, 80804.63 \mathrm{MJha}^{-1}$ respectively. In grown haylage vetch+triticale, the highest energy terms usage proportion in total energy was found $35.39 \%$ with packaging energy. Seed, fertilizer energy, fuel-oil energy and machinery energy were followed 26.36\%, 20.94\%, 13.78\% and $3.16 \%$ etc. respectively. This study can be used as a source of information for subject workers, policy makers and decision makers in terms of sustainable environment and energy.

Keywords: Haylage vetch+triticale production, energy balance, Adana

\section{GİRIŞ}

'Türkiye'de, hayvancılığın yem ihtiyacını meralar, tarla tarımı yapılan alanlardaki bitki artıkları, kaba yem (KY) bitkileri ve bazı yem bitkilerinden yapılan haylaj ve silaj ürünler oluşturmaktadır. Geleneksel silaj, \%25-30 kuru madde (KM) içeren bol su içeriği bulunan yemlerin parçalanarak sıkıştırılıp, havasız ortamda elde edilir. Ancak haylaj, silaja göre nem içeriği daha düşük (\%40-60 KM) olan ürünlerin; plastik ambalajlarla sarılarak balyalar halinde sıkıştırılıp havasız ortama bırakılarak hazırlanırlar (Kılıç, 2010; Kutlu ve Çelik, 2010). Haylaj üretimi ile Türkiye’de kaliteli yem açığını azaltmaya yönelik uygulamalara başlanmıştır.

Ülkemizde, tarımsal işletmelerin üretim durumuna göre \%62.3'ünde bitkisel ve hayvansal, \%37.2'sinde sadece bitkisel, \%0.5'inde sadece hayvansal üretim gerçekleşmektedir. $\mathrm{Bu}$ işletmelerde, hayvancılık işletmelerinin \%59.7'si 1-4, \%25.4’ü 10-19 adet büyükbaş hayvana sahiptirler. Buna göre, hayvancılık işletmelerinin genel olarak küçük aile işletmeleri olduğu görülmektedir. Ülkemizde 18.3 milyon büyükbaş ve 49.8 milyon küçükbaş hayvan varlığı mevcuttur (Anonim, 2019). Ülkemizde, sağlıklı ve ekonomik üretim amacıyla "yaşam payı+7 kg sütgün ${ }^{-1 " ' e ~ g o ̈ r e ~ y 1 l l ı ~ K Y ~ i h t i y a c ı ~} 100$ milyon ton'dur. Fakat Türkiye'de KY üretimi 38.5 milyon ton olduğu düşünüldüğünde, 61.5 milyon ton nitelikli KY açığı olduğu söylenebilir (Ak, 2013). Küçük işletmelerin üretim girdi maliyetlerini düşürmek, kârlılıklarını artırmak amacıyla Tarım ve Orman Bakanlığının 2000 yılı itibariyle yaptığı desteklemelerle yem bitkileri üretiminde yükseliş olduğu bildirilmiştir (Akman vd., 2007). 2015 yılı kayıtlarına göre bu yükseliş ile birlikte toplam ekim alanlarının \%10.9'unda yem bitkisi üretimi gerçekleştiği izlenmiştir. Bu üretimde, bir kısmı geleneksel silaj, bir kısmı kuru ot ve bir kısmı da doğrudan otlatmada değerlendirilmiştir. Silaj, su bakımından zengin bitkilerin havasız ortamda fermantasyona uğratılması sonucu elde edilen üründür. Haylaj ise her türlü yem bitkilerinden yapılmakla birlikte, fiğ-tahıl karışımları haylaj yapılan bitkilerdendir.

Fiğ, baklagiller familyasından olup ot kalitesi bakımından zengin tek yıllık bir yem bitkisidir. Fiğ bitkileri belirli bir büyüklüğe varınca gövdelerinin zayıflı̆̆ı nedeniyle kendi 
ağırlığını taşıyamadığından kolayca yatarlar. Yatmış olan fiğ bitkisinde ise hem hasat güçleşir, hem de çürümeler ortaya çıkar. Bunların sonucunda da otun verimi ve kalitesi düşer. $\mathrm{Bu}$ nedenle fiğ bitkisinin yatmaması ve kaliteli ot üretimi için tahıllarla birlikte ekilmesi tavsiye edilir. Fiğtahıl karışımında tahıl olarak tritikale, arpa, buğday, yulaf gibi bitkiler kullanılmaktadır.

Adana'da hem ana ürün hem de ikinci ürün olarak çeşitli ürünler yetiştirilmektedir. Ana ürünlerin ekimi genellikle mart veya nisan ayında yapılmaktadır. Nisan ayında ekimi yapılan ürünler için toprak bir önceki ürünün hasadından sonra nisan ayına kadar boş kalmaktadır. Toprak yaklaşık olarak 5 ay boyunca değerlendirilmemektedir. Özellikle kasım ayından nisan ayı ortasına kadar boş kalan ekim alanlarının bu yoldan üretime katılması, hayvancılığın temel girdilerinden biri olan kaliteli kaba yem açığının kapatılmasında büyük katkılar sağlayacaktır.

Adana ilinde, 2017 yılı tarımsal yapı ve üretim verilerine göre hayvan varlığı, 235141 büyükbaş ve 776049 küçükbaş hayvan olarak belirtilmiştir (Anonim, 2017a). 2016 yılında yetiştirilen yem bitkilerinin ekili alan durumuna göre; fiğ: 718.8 ha, korunga: 35.5 ha, sorgum: 58.8 ha, yonca: 129.7 ha, tritikale: 60.0 ha, yulaf: 75.0 ha ve silajlı mısır: 4973.1 ha olarak gerçekleşmiştir (Anonim, 2017b). Elde edilen ürün genel olarak yeşil ot (kuru madde oranı >\%35) olarak değerlendirilmektedir. Ancak yörede, haylajlık fiğ+tritikale üretimi kayıtlarına ulaşılamamıştır.

Çiftçiler, tarımsal alanlarını büyütme yerine daha çok girdi kullanmak ve üretim değerini çoğaltmaya çalışmaktadırlar. Bunun dışında, etkili ve alternatif enerji kullanma yönünden bilinç düzeyi bakımından yeterli değildirler (Yilmaz vd., 2010). Tarımsal üretimdeki girdilerin toplam enerji değerinin, çıktı ürünün enerji değeri ile kıyaslaması, üretim verimliliğinin karşılaştırılması açısından daha gerçekçi bir yaklaşımdır (Öztürk, 2011). Enerji çıktı/girdi kıyaslanması ile enerjinin ne kadar verimli değerlendirildiği, nihayetinde tarımın sürdürülebilir hale gelmesi, fosil yakıtların tüketiminin azaltılması, ekonomik faydanın dışında çevrenin korunması için tarımsal üretimde verimli enerji kullanımı faydalıdır (Bilgili, 2012). Aksi durum girdi maliyetlerini de olumsuz yönde etkilemektedir. Bu çalışmada, Adana ilinde döner tamburlu makina ile haylaj olarak fiğ+tritikale karışımı üretiminde enerji etkinliği tespit edilmiştir.

\section{MATERYAL VE YÖNTEM}

Bu çalışma, Adana ili (36 $51^{\prime} 20^{\prime \prime} \mathrm{K}$ ve $35^{\circ} 20^{\prime} 46^{\prime \prime}$ D, rakım $12 \mathrm{~m}$ ) koşullarında yürütülmüştür. Yörede, tipik Akdeniz iklimi özellikleri hâkimdir. Araştırmanın yürütüldüğü (Kasım 2015, Mayıs 2017) dönemlerde, yağış ortalaması miktarı $291.8 \mathrm{~mm}$, nem \%68.1 ve dönemlik sıcaklık ise $16.1{ }^{\circ} \mathrm{C}$ dir (MGM, 2017). Deneme alanı toprağının 0-30 $\mathrm{cm}$ derinliğindeki bazı fiziksel ve kimyasal özellikleri: $\mathrm{pH}, 7.8, \% 16.1$ kireç, \%2.3 organik madde, \%7.4 EC, $48\left(\mathrm{kgha}^{-1}\right)$ P, $1163\left(\mathrm{kgha}^{-1}\right) \mathrm{K}$, bünye, killi tınlı olarak hesaplanmıştır. Araştırmada, fiğ +tritikale karışımı üretimi sürecinde kullanılan girdi değerleri ve elde edilen çıktı değerleri ayrıca alet-makinaların teknik özellikleri yöredeki uygulama yöntemlerinden, literatürden, önceki çalışmalardan ve teknik kataloglardan elde edilmiştir.

Adana’da fiğ+tritikale üretiminde kullanılan girdilerden ortalama gübre miktarı ekim ile birlikte tamamı saf 50 kgha $^{-1}\left(\mathrm{P}_{2} \mathrm{O}_{5}\right)$ fosfor ve $50 \mathrm{kgha}^{-1}(\mathrm{~N})$ azot (Yücel ve Avcı. 2009), ortalama tohum miktarı (\%56 fiğ $+\% 44$ tritikale), $100 \mathrm{kgha}^{-1}$ fiğ tohumu ile $80 \mathrm{kgha}^{-1}$ tritikale tohumu olarak uygulanmıştır. Çalışmada, fiğttritikale

Çizelge 1. Haylaj yapımı için fiğ+tritikale üretiminde kullanılan makina ve aletlerin teknik özellikleri

\begin{tabular}{|l|c|c|c|c|}
\hline Makina & $\begin{array}{c}\text { İş genişliği } \\
(\mathrm{cm})\end{array}$ & $\begin{array}{c}\text { İş derinliği } \\
(\mathrm{cm})\end{array}$ & $\begin{array}{c}\text { Ortalama çalışma hızı } \\
\left(\mathrm{kmh}^{-1}\right)\end{array}$ & $\begin{array}{c}\text { Ağırlık } \\
(\mathrm{kg})\end{array}$ \\
\hline Çizel & 210 & $15-30$ & 5.7 & 550 \\
\hline Goble disk & 210 & $0-10$ & 6.4 & 1020 \\
\hline Hububat ekim makinası & 300 & $3-5$ & 6.7 & 950 \\
\hline Tamburlu çayır biçme makinası & 165 & - & 4.6 & 360 \\
\hline
\end{tabular}


Çizelge 2. Adana’da haylajlık fiğ+tritikale üretimindeki bazı kültürel faaliyetler

Kültürel faaliyetler Uygulamanın özelliği

Toprak işleme

Toprak, sonbaharda çizel ile işlendikten sonra gobledisk ile 2 kez çapraz olarak sürülmüş̧ür.

Kasım ayında hububat ekim makinası ile fiğ+tritikale karışımı $100 \mathrm{kgha}^{-1}$

Ekim fiğ ile $80 \mathrm{kgha}^{-1}$ tritikale karıştırılmış ve ekimi yapılmıştır. Ekim işlemi sırasında saf $50 \mathrm{kgha}^{-1}$ fosfor ve $50 \mathrm{kgha}^{-1}$ azot olacak şekilde gübreleme yapılmıştır.

Bitki kuru madde içeriğinin \%35-40 olduğu dönemlerde yapılmıştır. Bu

Hasat dönemde fiğ bitkisi yaklaşık olarak \%10 çiçeklenme ve tritikale bitkisi süt olum dönemi olduğunda döner tamburlu biçme makinası ile hasat yapılmıştır.

karışımının yetiştirilme döneminde herhangi bir ilaçlama ve sulama yapılmamıştır. 2015-2017 yılları için Adana'da fiğ +tritikale karışımı ortalama verimi $10785 \mathrm{kgha}^{-1}$ olarak gerçekleşmiştir. Haylajllk fiğgttritikale üretiminde herhangi bir kimyasal ilaç kullanılmadığından dolayı ve kışın yağmur suyu ile ihtiyacını karşıladığı için kimyasal ilaç enerji girdisi ve sulama enerji girdisi hesaplanmamıştır. Fiğ+tritikale karışımı yetiştiriciliğinde kullanılan makina ve Fiğ+tritikale karışımı yetiştiriciliğinde enerji verimliliğinin tespiti için enerji girdi ve çıktılarının hesaplanması gerekir. Enerji girdileri gübre, tohum, insan iş gücü, makina iş gücü ve yakıt-yağ enerjisinden oluşmaktadır. Enerji girdisi ve çıktısının hesaplanmasında girdi ve çıktı çeşitlerinin enerji eş değerleri bilinmelidir. Enerji eşdeğerlerinin tespitinde önceki çalışmalardan (Çizelge 3) faydalanılmıştır.

aletlerin teknik değerleri Çizelge 1'de, fiğ+tritikale karışımı üretiminde yapılan işlemler Çizelge 2'de verilmiştir.

Çizelge 3. Tarımsal üretimde girdi/çıktıların enerji eşdeğeri parametreleri

\begin{tabular}{|c|c|c|}
\hline Girdi & $\begin{array}{l}\text { Enerji eşdeğeri } \\
\left(\text { MJbirim }^{-1}\right)\end{array}$ & Referanslar \\
\hline İnsan İşgücü (h) & 2.3 & Bilgili, 2012 \\
\hline \multicolumn{3}{|l|}{ Makina üretim enerjisi (kg) } \\
\hline Traktör & 158.3 & Barut vd., 2011; Gözübüyük vd., 2012 \\
\hline Toprak işleme aletleri & 121.3 & Barut vd., 2011; Gözübüyük vd., 2012 \\
\hline \multicolumn{3}{|l|}{ Yaklt $(L)$} \\
\hline Dizel & 35.69 & Eren, 2011; Sabah, 2010; Arıkan, 2011 \\
\hline Yağ & 6.51 & Eren, 2011; Sabah, 2010; Arıkan, 2011 \\
\hline \multicolumn{3}{|l|}{ Kimyasal Gübreler (kg) } \\
\hline Azot $(\mathrm{N})$ & 60.6 & $\begin{array}{l}\text { Singh, 2002; Demircan vd., } 2006 \\
\text { Öztürk, 2011; Barut vd., } 2011\end{array}$ \\
\hline Fosfor $\left(\mathrm{P}_{2} \mathrm{O}_{5}\right)$ & 11.1 & $\begin{array}{l}\text { Singh, 2002; Demircan vd., } 2006 \\
\text { Öztürk, 2011; Barut vd., } 2011\end{array}$ \\
\hline Ambalaj ve İp & 60 & Hetz, 1998. \\
\hline \multicolumn{2}{|l|}{ Tohum (kg) } & Bilgili vd., 2019 \\
\hline \multicolumn{3}{|l|}{ Çıktı } \\
\hline Fiğ +tritikale Karışımı & 9.08 & Civaner, 2015 \\
\hline
\end{tabular}




\section{Enerji Girdileri:}

Makina Enerjisi $\left(M^{\prime} a^{-1}\right)$ : Eşitlik 1 ile hesaplanmıştır (Yaldız vd., 1990; Öztürk, 2011).

$\mathbb{E I}=\frac{A \times E}{T \times E A K}$

Burada;

ME : Makina enerji $\left(\mathrm{MJha}^{-1}\right)$,

AA : Aletin ağırlığı $(\mathrm{kg})$,

E :Tarım makinasının veya aletin birim ağırlığının üretim enerjisi $\left(\mathrm{MJkg}^{-1}\right)$,

$\mathrm{T} \quad$ : Traktör veya aletin ekonomik kullanım süresi (h),

EAK : Efektif alan kapasitesi $\left(\text { hah }^{-1}\right)^{\prime}$ dır.

Yakıt-Yăg Enerji $\left(M J h a^{-1}\right)$ : Eşitlik 2 ve 3 ile tespit edilmiştir (Gözübüyük vd., 2012).

$\mathrm{YE}=\mathrm{YT} \times \mathrm{YED}$

$\mathrm{YaE}=(\mathrm{YT} \times 0.045) \times \mathrm{YaED}$

Burada;

YE $\quad$ : Yakıt enerjisi $\left(\mathrm{MJha}^{-1}\right)$

YaE : Yağ enerjisi $\left(\mathrm{MJha}^{-1}\right)$

YT : Yakıt tüketimi $\left(\right.$ Lha $\left.^{-1}\right)$

YED : Yakıtın enerji değeri $\left(\mathrm{MJL}^{-1}\right)$

YaED : Yağın enerji değeri $\left(\mathrm{MJL}^{-1}\right)^{\prime}$ dir.

Tarımsal üretimde, tarla üretim işlemlerinde aletmakinalarının kullanımında traktör tarafından tüketilen motorinin özgül kütlesi $0.83 \mathrm{kgL}^{-1}$ ve alt 1sıl değeri 43 $\mathrm{MJkg}^{-1}$ (35.69 $\mathrm{MJL}^{-1}$ ) esas alınmıştır (Eren, 2011). İnsan iş gücü enerjisi, gübre ve tohum enerji girdisi hesabı, alan başına harcanan veya kullanılan girdi değeri ve bu girdi çeşitlerinin enerji eşdeğerinin çarpan olarak kullanılması ile hesaplanmıştır.

Haylajlık, fiğ +tritikale karışımı üretimi sürecinde enerji girdileri iki grupta değerlendirilmiştir. Bunlar, "doğrudan" ve "dolaylı" enerji girdileridir. Fiğ+tritikale haylajı üretimindeki tarım alet-makinaların harcadığı yakıt-yağ enerji değerleri "doğrudan enerji” olarak hesaplanmışır. "Dolaylı enerji" girdisi olarak, kullanılan tohumluk ve gübre üretimi için tüketilen enerji miktarları ayrıca insan iş gücü ve tarım alet-makinaları değerleri hesaplamada kullanılmıştır (Öztürk, 2011). Bitkisel üretimde, 1 ha'lık üretim alanında kullanılan enerji "Toplam Enerji Girdisi (EIT)" olarak ifade edilmiştir.

\section{Enerji Çıktıları:}

Birim alandan sağlanan enerji miktarı Eşitlik 4 ile hesaplanmıştır (Öztürk, 2011).

Tec $=($ AuvxEaü $)+($ YuvxEyu $)$

Burada;

Tec : $\quad$ Toplam enerji çıktısı $\left(\mathrm{MJha}^{-1}\right)$,

Auv : $\quad$ Ana ürün verimi $\left(\mathrm{kgha}^{-1}\right)$,

Yuv : $\quad$ Yan ürün verimi $\left(\mathrm{kgha}^{-1}\right)$,

Eau : Ana ürünün enerji eşdeğeri $\left(\mathrm{MJkg}^{-1}\right)$ ve

Eyu : Yan ürünün enerji eşdeğeri $\left(\mathrm{MJkg}^{-1}\right)^{\prime}$ 'dür.

Enerji verimliliğinin tespiti için Çizelge 4'de verilen parametrelerden faydalanılmıştır (Eren, 2011).

Çizelge 4. Enerji etkinliği göstergeleri

\begin{tabular}{ll}
\hline Parametreler & Tanım \\
\hline \multirow{2}{*}{ Enerji Oranı } & Enerji Çıktısı (EO)/Toplam Enerji \\
& Girdisi (EIT) \\
\hline Özgül Enerji (MJkg- & EIT/Hasat Edilen Toplam Ürün \\
& Miktarı \\
\hline Enerji Üretkenliği & Hasat Edilen Toplam Ürün Miktarı/ \\
$\left(\mathrm{kgMJ}^{-1}\right)$ & EIT \\
\hline Net Enerji Üretimi & Toplam Enerji Çıktısı - Toplam \\
$\left(\mathrm{MJha}^{-1}\right)$ & Enerji Girdisi \\
\hline
\end{tabular}

\section{BULGULAR VE TARTIŞMA}

Fiğ+tritikale üretiminde giren ve çıkan enerji toplam enerji değerleri ve enerji etkinliği göstergeleri Çizelge 5 'te gösterilmiştir. Enerji girdileri içerisinde en yüksek enerji girdisi \%35.39 oranına karşılık gelen 6060.00 MJha 1 enerjiyle ambalaj malzemeleri (PE ve ip) enerjisinde gerçekleşmiştir. Tüm girdiler içerisinde tohum enerji girdisi $4514.00 \mathrm{MJha}^{-1}$ olarak tüketilerek \%26.36 oranı 
Çizelge 5. Döner tamburlu hasat makinası ile fiğ+tritikale karışımı haylaj üretiminde enerji kullanımı

\begin{tabular}{|c|c|c|c|}
\hline Girdi & $\begin{array}{l}\text { Hektar Başına } \\
\quad \text { Miktar }\end{array}$ & $\begin{array}{l}\text { Toplam Enerji Girdisi } \\
\qquad\left(\mathrm{MJha}^{-1}\right)\end{array}$ & $\begin{array}{c}\text { Toplam Enerji } \\
\text { Girdisine Oran1 (\%) }\end{array}$ \\
\hline İnsan İşgücü (h) & 27.59 & 63.46 & 0.37 \\
\hline Toprak Hazırlama İşlemleri & 4.68 & 10.75 & \\
\hline Ekim ve Diğer İşlemler & 2.35 & 5.41 & \\
\hline Hasat & 20.56 & 47.29 & \\
\hline Makina $(h)$ & 20.84 & 540.37 & 3.16 \\
\hline Traktör & 4.71 & 107.37 & \\
\hline Toprak Hazırlama İşlemleri & 4.68 & 56.67 & \\
\hline Ekim ve Diğer İşlemler & 1.18 & 129.86 & \\
\hline Hasat & 10.28 & 246.46 & \\
\hline 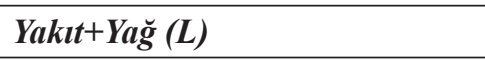 & 68.54 & 2359.94 & 13.78 \\
\hline Toprak Hazırlama İşlemleri & 31.03 & 1068.33 & \\
\hline Ekim ve Diğer İşlemler & 7.34 & 252.78 & \\
\hline Hasat & 30.17 & 1038.83 & \\
\hline Kimyasal Gübreler (kg) & 100.00 & 3585.00 & 20.94 \\
\hline Fosfor $(\mathrm{P})$ & 50.00 & 555.00 & \\
\hline $\operatorname{Azot}(\mathrm{N})$ & 50.00 & 3030.00 & \\
\hline Ambalaj (kg) & 101.00 & 6060.00 & 35.39 \\
\hline PE ve İp malzemeleri & 101.00 & 6060.00 & \\
\hline Tohum (kg) & 180.00 & 4514.40 & 26.36 \\
\hline Toplam Enerji Girdisi (MJha ${ }^{-1}$ ) & & 17123.17 & 100.00 \\
\hline Doğrudan Enerji Girdisi & & 2359.94 & \\
\hline Dolaylı Enerji Girdisi & & 14763.23 & \\
\hline \multicolumn{4}{|l|}{ Çıktı $\left(k g h a^{-1}\right)$} \\
\hline Verim & 10785.00 & 97927.80 & \\
\hline Toplam Enerji Çıktısı (MJha-1) & & 97927.80 & \\
\hline Enerji Oranı & \multicolumn{3}{|c|}{5.72} \\
\hline Özgül Enerji $\left(\mathrm{MJkg}^{-1}\right)$ & \multicolumn{3}{|c|}{1.59} \\
\hline Enerji Üretkenliği $\left(\mathrm{kgMJ}^{-1}\right)$ & \multicolumn{3}{|c|}{0.63} \\
\hline Net Enerji Verimi $\left(\mathrm{MJha}^{-1}\right)$ & \multicolumn{3}{|c|}{80804.63} \\
\hline
\end{tabular}

Ambalaj (PE+İp): Ambalaj malzemeleri, PE örtü malzemesi ve balya bağlama ipi.

ile en yüksek ikinci sırada yer almıştır. Kimyasal gübreler 3 585.00 $\mathrm{MJha}^{-1}$ tüketilerek \%20.94 oran ile üçüncü sırada yer almıştır. Fiğ +tritikale üretiminde yakıt-yağ enerji girdisi $2359.94 \mathrm{MJha}^{-1}$ değeri ile \%13.78 oranına sahip olmuştur. Fiğ+tritikale üretiminde alet/makina enerjisi için 1 ha alan için $540.37 \mathrm{MJ}$ enerji tüketilmiş, bu değer toplam enerji içerisinde \%3.16 oranına karşıllk gelmiştir. Birim alan başına $27.59 \mathrm{~h}$ insan iş gücüne karşıllk olarak 63.46
$\mathrm{MJha}^{-1}$ insan işgücü enerjisi tüketilmiş, bu değer $\% 0.15$ ile en düşük girdiyi oluşturmuştur (Çizelge 5). Fiğ+tritikale üretimi için elde edilen toplam enerji girdisi $17 \quad 123.17$ $\mathrm{MJha}^{-1}$, toplam enerji çıktısı $97927.80 \mathrm{MJha}^{-1}$, enerji oranı 5.72, özgül enerji $1.59 \mathrm{MJkg}^{-1}$, enerji üretkenliği $0.63 \mathrm{kgMJ}^{-1}$ ve net enerji verimi $80804.63 \mathrm{MJha}^{-1}$ olarak gerçekleşmiştir (Çizelge 5). 
2015-2017 yılları arasında Adana'da yürütülen bu araştırmada, döner tamburlu makina ile haylajlık fiğg+tritikale üretiminde enerji etkinliğinin hesaplanması amaçlanmıştır. Hesaplamalar sonucunda, üretim girdileri içerisinde en yüksek payı ambalaj enerjisi (\%35.39) almıştır. Bunu sırasıyla \%26.36 ile tohum enerjisi, \%20.94 ile gübre enerjisi, \%13.78 ile yakıt-yağ enerjisi ve \%3.16 ile makina işgücü enerjisi vd. takip etmiştir. Kökten ve ark., (2017) bir fiğ çeşidi üretiminde enerji etkinliğinin hesaplanmasında \%24.11 oranında tohum enerjisi girdisini hesaplamışlardır. Türkiye'de tarla bitkileri üretimi sürecinde tohum enerjisi girdisi \%14.8 olarak hesaplanmıştır (Yaldız vd., 1990). Yapılan bu araştırmada, tohum kullanım enerjisi (\%26.36) oransal olarak önceki çalışmalara göre farklılık göstermiştir. Haylajlık fiğ+tritikale üretimi sürecindeki gübre enerjisi \%20.94 olarak hesaplanmıştır. Kökten, ve ark., (2017), kimyasal gübre enerjisini \%17.12 olarak tespit etmişlerdir. Yaldız vd., (1990)'a göre Türkiye genelinde tarla bitkileri üretimi sürecinde enerji açısında en çok $\% 45.8$ girdi gübreden kaynaklandığını belirtmişlerdir. Araştırmada, gübre kullanım enerjisi oransal olarak önceki çalışmalara göre oransal olarak 3. sırada yer almıştır. Yakıt-yağ enerjisi \%13.78 olarak hesaplanmış ancak Kökten vd., (2017), tarafından yapılan çalışmada bu değer \%30.10 oranında değerlendirilmiştir. Bu enerji kullanımı, Türkiye'de tarla bitkileri üretiminde \%12 olarak hesaplanmıştır (Yaldız vd., 1990). Makina enerjisi \%3.16 olarak belirlenmiştir. Bu oran Türkiye'de tarla bitkileri üretiminde \%6.7 gibi bir değere sahiptir (Yaldız vd., 1990). Makina kullanım enerjisi ülke ortalamasına göre düşük seviyede bulunmuştur. Son olarak kullanılan enerji ise insan iş gücü enerjilerinin (\%0.37) izlediği görülmektedir. Bu durum, Yaldız vd, (1990) tarafından yapılan, Türkiye genelinde tarla bitkileri üretiminde enerji açısında en fazla girdiye sahip olan gübre (\%45.8), bunu tohumluk (\%14.8) ve yakıt-yağ (\%12) girdi enerjisini takip etmiş olduğu çalışması ile benzerlik göstermiş olup makina ve insan işgücü enerjisi kullanımında farklılık göstermiştir.

Kökten vd., (2017), yaptıkları çalışmada, fiğ üretiminden kârlılığı, enerji kullanım verimliliği açısından değerlendirerek çıktı/girdi oranın 0.81 değeri gibi düşük olduğundan; kârlı bir iş olmadığını belirtmişlerdir. Daha önceki çalışmalarda, Baran ve Gökdoğan (2014) arpa için enerji çıktı/girdi oranını 5.44 olarak hesaplamış, Ghorbanie vd., (2011) arpa bitkisi için hesaplanan enerji çıktı/girdi oranı 2.56 ve buğday için 1.97, Vural ve Efecan (2012), enerji çıktı/girdi oranını mısır için 0.76 olarak hesaplamışlardır. Akpınar ve ark. (2009) susam için iki çalışma yapmışlardır. Enerji çıktı/girdi oranı 1.80 ve 1.40 olarak hesaplamışlardır. Pisghar- Komleh vd., (2011) susam için enerji çıktı/girdi oranını 1.53 olarak hesaplamıştır. Adana'da haylaj fiğ +tritikale tarımında enerji çıktı/girdi oranı 5.72 göz önüne alındığında enerji açısından verimli bir üretim yapıldığı söylenebilir.

\section{SONUÇ VE ÖNERILLER}

Bu çalışma, Adana ili koşullarında 3 yıl (2015-2017) süre ile fiğ+tritikale karışımının tarımsal üretim döneminde yetiştirilmesi sonucu elde edilen bazı verileri sunulmuştur

Yem bitkilerinden ekonomik ve kaliteli haylaj elde etmek amacıyla dört farklı uygulama yapılmıştır. Bunlardan bir tanesi de döner tamburlu makina ile hasad edilen fiğ+tritikale karışımının biçilerek; kurumasının hızlandırılmasıdır.

Döner tamburlu makina ile haylaj üretiminde, enerji bilançosu ortaya konulmuştur.

Enerji bilançosundaki amaç, tarımsal üretim uygulamalarında kullanılan toplam girdilerin enerji değerleri ile elde edilen ürünlerin enerji değerlerinin hesaplanması sonucu enerjinin ne kadar verimli kullanılıp kullanılmadığının belirlenmesidir.

○ Çiftçiler, üretim alanlarını büyütmeden, daha fazla girdi kullanarak üretim miktarlarını çoğaltmaya çalışmaktadırlar.

Bu bağlamda, ekonomiklik ve sürdürülebilirlik için tarımsal üretimde verimli enerji kullanımı önemlidir.

$\mathrm{Bu}$ amaçla, üretimde kullanılan makinaların ve aletlerin ekonomik ömürleri, iş başarıları, yakıt ile yăg tüketimleri, makina ağırlıkları, gübre, tohum miktarları gibi temel veriler kullanılmıştır.

Sonuç olarak; haylajlık fiğ+tritikale yetiştiriciliğinde enerji çıktı/girdi oranı 5.72, özgül enerji 1.59 $\mathrm{MJkg}^{-1}$, net enerji değeri $80804.63 \mathrm{MJha}^{-1}$ olarak hesaplanmıştır. Toplam enerji girdileri içerisinde 
kullanım oranı en çok olanın \%35.39 ile ambalaj (PE ve ip) olduğu hesaplanmıştır. Bunu sırasıyla \%26.36 ile tohum, \%20.94 ile gübre enerjisi, \%13.78 ile yakıt-yağ ve \%3.16 ile makina işgücü enerjisi vd. takip etmiştir.

Bu sonuçlara göre tarımsal üretimde alternatif ürünler ya da üretim yöntemleri ve girdiler önerilebilir.

$\square$ Sürdürülebilir çevre ve enerji açısından konu çalışanları, politika üreticileri ve karar vericiler için veri seti olarak kullanılabilir.

\section{TEŞEKKÜR}

$\mathrm{Bu}$ çalışma, TAGEM/TSKAD/14/A13/P08/06 no'lu projeden üretilmiştir. TAGEM'e teşekkür ederiz.

Yazarlar, Araştırma ve "Yayın Etiğine” uyulduğunu beyan ederler.

Araştırmacılar, "Katkı Oranına” göre yazarlar sıralamasına uyulmuş olup, herhangi bir "Çıkar Çatışması" bulunmadığını beyan ederler.

\section{KAYNAKLAR}

Ak, İ. (2013). Türkiye de Kaba Yem Sorunu ve Çözüm Önerileri. VII. Ulusal Hayvan Besleme Kongresi (Uluslar Arası Katılımlı) Sözlü Bildiriler, 1-12 s. 2627 Eylül 2013. Ankara.

Akman, N., Aksoy, F., Şahin, O., Kaya., Y., ve Erdoğdu, G. (2007). Cumhuriyetimizin 100. Yılında Türkiye'nin Hayvansal Üretimi. Türkiye Damızlık Sı̆̆ır Yetiştiriciliği Birliği Yayınları, cilt: 4. 6-7s.

Akpınar, M.G., Ozkan, B., Sayin, C., Fert, C. (2009). An Input-Output Energy Analysis on Main and Double Cropping Sesame Production. Journal of Food, Agriculture \& Environment 7 (3-4): 464- 467.

Anonim, (2017a). Adana ili tarımsal yatırım rehberi. https://www.tarimorman.gov.tr /SGB/TARYAT/ Belgeler/ il_yatirim_rehberleri /adana.pdf, erişim tarihi 02.02.2020

Anonim, (2017b). Türkiye İstatistik Kurumu Yem Bitkileri Ekiliş Alanları Verileri. https://biruni. tuik.gov.tr/bitkiselapp/bitkisel.zul, erişim tarihi, 04.01 .2020

Anonim, (2019). Hayvan Sayıları. https://www. tarimorman.gov.tr/sgb/Belgeler/SagMenu Veriler/ HAYGEM.pdf, erişim tarihi, 05.01.2020
Arıkan, M. (2011). Adana İlinde Kolza Üretiminde Enerji Kullanımı. Çukurova Üniversitesi. Fen Bilimleri Enstitüsü, Tarım Makinaları Anabilim Dalı. Yüksek Lisans Tezi. 65s.

Baran, M.F., and Gökdoğan, O. (2014). Energy InputOutput Analysis of Barley Production in Thrace Region of Turkey. American- Eurasian J. Agric. \& Environ. Sciences, 14 (11): 1255-1261.

Barut, Z.B., Ertekin, C., and Karaağaç, H.A. (2011). Tillage Effects on Energy Use for Corn Silage in Mediterranean Coastal of Turkey. Energy. 36 (9): 5466-5475.

Bilgili, M.E. (2012). Limon Üretiminde Enerji Kullanım Etkinliğinin Belirlenmesi; Adana İli Örneği. Tarım Makinaları Bilimi Dergisi. 8 (2): 199-203.

Bilgili, M.E., Vurarak,Y. ve İnce. A. (2019). Adana koşullarında ezme üniteli makina ile fiğ+tritikale karışımından haylaj üretiminde enerji kullanım etkinliğinin belirlenmesi. Çukurova II. Uluslararası Multidisipliner Çalışmalar Kongresi 26-28 Nisan 2019 ADANA.

Civaner, A.G. (2015). Batı Akdeniz Bölgesinde Yetiştirilen

Bazı Yem Hammaddelerinin Besin Madde İçeriklerinin Belirlenmesi Üzerine Bir Araştırma. Akdeniz Üniversitesi Fen Bilimleri Enstitüsü. Doktora Tezi Zootekni Anabilim Dalı. 71s. Antalya. Demircan, V., Ekinci, K., Keener, H., Akbolat, D., and Ekinci, C. (2006). Energy and Economic Analysis of Sweet Cherry Production in Turkey: A Case Study from Isparta Province. Energy Conversion and Management. 47 (13-14), 1761-1769.

Eren, Ö. (2011). Çukurova Bölgesinde Tatlı Sorgum üretiminde Yaşam Döngüsü Enerji ve Çevresel Etki Analizi. Çukurova Üniversitesi. Fen Bilimleri Enstitüsü, Tarım Makinaları Anabilim Dalı. Doktora Tezi. 197s. Adana.

Ghorbani, R., Mondani, F., Amirmoradi, S., Feizi, H., Khorramdel, S., Teimouri, M., Sanjani, S., Anvarkhah, S., Aghel, H. (2011). A Case Study of Energy Use and Economical Analysis of irrigated and Dryland Wheat Production Systems. Applied Energy, 88 (1): 283-288.

Gözübüyük, Z., Çelik, A., Öztürk, İ., Demir, O., Adıgüzel, 
M.C. (2012). Buğday Üretiminde Farklı Toprak İşleme- Ekim Sistemlerinin Enerji Kullanım Etkinliği Yönünden Karşılaştırılması. Tarım Makinaları Bilimi Dergisi. Cilt 8 (1). 25-34.

Hetz, E.J. (1998). Energy Utilization in Fruit Production in Chile. Agricultural Mechanization in Asia, Africa, and Latin America (AMA), 29 (2):17-20.

Kilıç, A. (2010). Silo Yemi (öğretim-öğrenim ve uygulama örnekleri) El Kitabı. Hasad Yayıncilık, İstanbul, s: 263.

Kökten, K., Cacan, E., Gökdoğan, O., Baran, M.F. (2017). Determination of Energy Balance of Common Vetch (Vicia Sativa L.), Hungarian Vetch (Vicia Pannonica C.) and Narbonne Vetch (Vicia Narbonensis L.) Production in Turkey. Legume Research-An International Journal. 40 (3): 491-496.

Kutlu, H.R., Çelik, L. (2010). Yemler Bilgisi ve Yem Teknolojisi. Çukurova Üniversitesi Ziraat Fakültesi. Genel Yayın No: 266, Kitap Yayın No: A-86. Adana. MGM, (2017). Adana İli İklim Verileri. https://www. mgm.gov.tr/ erişim tarihi, 03.01.2020

Öztürk, H.H. (2011). Bitkisel Üretimde Enerji Yönetimi. Hasad Yayıncllı. Kod no: 296: 167-196. İstanbul.

Pishgar-Komleh, S.H., Sefeedpari, P., Rafiee, S. (2011). Energy and Economic Analysis of Rice Production Under Different Farm Levels in Gulian Province of Iran. Energy 36(10): 5824-5831.

Sabah, M. (2010). Söke Ovasında İkinci Ürün Yağlık Ayçiçeği Üretiminde Enerji Kullanımı. Çukurova Üniversitesi Fen Bilimleri Enstitüsü Tarım Makinaları Anabilim Dalı. Yüksek Lisans Tezi. 100s. Adana.

Singh, J.M. (2002). On Farm Energy Use Pattern in Different Cropping Systems in Haryana, India. International Institute of Management University of Flensburg, Sustainable Energy Systems and Management. Master of Science Thesis. Germany.

Vural, H., and Efecan, I. (2012). An Analysis of Energy Use and input Costs for Maize Production in Turkey. Journal of Food, Agriculture \& Environment10 (2 part 2): 613-616.

Yaldız, O., Öztürk, H.H., Zeren, Y., Başçetinçelik, A. (1990). Türkiye Tarla Bitkileri Üretiminde Enerji
Kullanımı. Akdeniz Üniversitesi Ziraat Fakültesi Dergisi. 3 (1-2), 51-62. Antalya.

Yılmaz, İ., Özalp, A., Aydoğmuş, F. (2010). Antalya İli Bodur Elma Üretiminde Enerji Kullanım Etkinliğinin Belirlenmesi: Elmalı İlçesi Örneği. Akdeniz Üniversitesi Ziraat Fakültesi Dergisi, 23(2): 93-97.

Yücel, C., Avc1, M. (2009). Effect of Different Ratios of Common Vetch-Triticale Mixtures on Forage Yields and Quality in Cukurova Plain in Turkey. Bulgarian Journal of Agricultural Science, Agricultural Academy. 15 (4), 323-332. 